\title{
Cancer Related Fatigue and Optimism in Cancer Patients
}

\author{
Raisa V. Strebkova ${ }^{1},{ }^{*} \&$ Miroslava P. Petkova \\ ${ }^{1}$ Department of "Medical psychology and foreign languages", Medical Faculty, Trakia University, Stara Zagora, \\ Bulgaria \\ *Correspondence: Department of "Medical psychology and foreign languages", Medical Faculty, Trakia University, \\ Armeyska Street N11, Stara Zagora, Bulgaria. E-mail: raja1@abv.bg
}

Received: June 1, 2018

Accepted: June 28, 2018 Online Published: July 22, 2018

doi:10.5430/wjss.v5n2p40

URL: https://doi.org/10.5430/wjss.v5n2p40

\begin{abstract}
Summary: The symptoms of fatigue and exhaustion are considered to be the most common complaints among patients with malignant diseases during the process of treatment and upon its completion. The manifestations of fatigue can be physical, cognitive and emotional. Particularly interesting are the risk factors for the emergence of fatigue which persists for months or years upon the completion of the treatment. A number of studies have discussed the significance of the psychological factors such as the personality traits, the person's behaviour and the lifestyle. Objective: To examine the burden of fatigue among patients with malignant diseases undergoing radiotherapy and long-term survivors and determine the effect of optimism on the burden of fatigue among them. Method: A questionnaire; MFI-20-A multidimensional questionnaire on fatigue; Method of examining the generalized expectations about the valence of the obtained results. 66 people with a confirmed oncological diagnosis were included in the study, 36 of whom were undergoing radiotherapy at the time of the study. 30 of the examined people have undergone radiotherapy and are presently long-term survivors who have lived over five years after being diagnosed with the disease. Conclusion: The patients that were undergoing radiotherapy at that time manifested more evident symptoms of fatigue within the dimensions of decreased motivation and decreased activity compared to the patients belonging to the group of the long-term survivors. Optimism and the negative expectations correlate significantly with the dimensions of fatigue in both groups of patients, as the most obvious is the negative correlation of optimism with the decreased activity and the decreased motivation. The presence of optimism and low negative expectations within the personality profile of patients with oncological diseases suggests lower levels of fatigue regardless of the stage of the disease and the conducted treatment.
\end{abstract}

Keywords: cancer related fatigue, optimism, radiotherapy patients, survivors

\section{Introduction}

Over the last decades, with the rise of the percentage of cancer survivors as a result of the advance in the treatment of oncological diseases and their early detection, the scientific efforts were focused on analyzing the quality of life and the psychological functioning during the treatment and upon its completion instead of being focused solely on the manifestations of the disease (Petkova \& Nikolov, 2011).

The official statistical data show that in 2013 in Bulgaria, the registered cases of malignant diseases were 3702.4/100 000 cases, of which 432.4 were newly detected. In 2014, the number of the registered cases rose to 3819.0/100 000 cases, as the newly detected ones were 461.9. The data show that the largest relative share within the structure of the cancer morbidity is that of the female breast cancer $102.7 / 100000$, the prostate gland cancer $79.9 / 100000$, the lung cancer 95.1/100 000 men and 21.4/100 000 women, the colorectal carcinoma 41.2/100 000 men, 32.7/100 000 women and other localizations (Valerianova, 2015). The estimated and observed 5-year cancer survival in Bulgaria within the period $2000-2005$ is $28 \%$, which is far below that of the economically developed countries. Bulgarian is at the bottom of the black list of oncological diseases survival (Valerianova, 2015). This determines the significance and the social damages that the society is currently suffering as a result of this disease. The symptoms of fatigue and exhaustion are considered to be the most common complaints among patients with oncological pathology during the treatment and after its completion and are jointly called (Cancer Related Fatigue) (Stone, Richards \& Hardy, 1998). According to the contemporary definition of the National Comprehensive Cancer Network (NCCN, 2011) fatigue is 
a restriction of physical and mental capacity which has occurred as a result of the medical treatment and significantly affects the activity of the patient and despite the adequate rest and relaxation it does not decrease. Kuhnt \& Brähler (2010) define fatigue as a multidimensional structure with typical symptoms: physical (physical exhaustion, fatigue), mental (sadness, irritability, hopelessness) and cognitive (concentration and memory disorders).

During the stage of diagnosing, up to $40 \%$ of the patients complaint about fatigue as this percentage rises to $90 \%$ in the course of treatment (de Vries, Reif \& Peterman, 2011), among $90 \%$ of the patients undergoing radiotherapy and $80 \%$ of the patients undergoing chemotherapy. The high values of fatigue duting the treatment can be lowered again upon its termination but compared to the values of physically healthy people and years later, the mean values of these patients are above the average (Simon \& Zittoun, 1999); (Woo, Dibble, Piper, Keating \& Weiss, 1998). Approximately a quarter up to one third of the cancer survivors manifest persisting fatigue within a period of up to 10 years after being diagnosed with the disease (Bower, Ganz, Desmond, Bernards, Rowland, Meyerowitz \& Belin, 2006) and this fatigue often causes significant disruptions in their functioning and quality of life.

Over the last few years, long-term studies have started examining the risk factors related to the emergence of fatigue and, in particular, the type of fatigue which persists for months or years upon the completion of the treatment (Bower, 2014). The studies in this area focus mainly on genetic, demographic, medical, behavioural and psychosocial predictors of the occurrence of fatigue. In addition to the factors related to the disease and its treatment (Bower, Ganz, Desmond, Rowland, Meyerowitz \& Belin, 2000); (Von Ah DM, Kang \& Carpenter, 2008) designate as a reason for the emergence of fatigue some psychological factors such as personality traits (optimism and anxiety) accompanying the physical symptoms, the lifestyle. Regardless of the behavioural studies, at present there is no overall concept explaining the reasons for its occurrence (Weis \&Faller, 2012).

Optimism has been defined as a relatively stable generalized trend - a summarized expectation for more positive things to happen and not negative ones (Schreier \& Carver, 1987). According to (Miller, Manne, Taylor, Keates \& Dougherty, 1996), optimism helps people adapt more successfully to the adverse events in their lives, including to serious diseases like "cancer".

In scientific literature there are data showing that optimism has a positive effect on overcoming and managing fatigue. A few studies have exmained the relation between optimism and fatigue among patients with oncological diseases (Von Ah DM et al., 2008); (Carver, Pozo, Harris, Noriega, Scheier, Robinson, Ketcham, Moffat \& Clark, 1993); (Allison, Guichard \& Gilain, 2000). The authors have established that the higher level of optimism is related to lower levels of fatigue. However, there are studies which do not confirm the relation between optimism and fatigue (Rotonda, Guillemin, Bonnetain, Velten, \& Conroy, 2013); (Servaes Verhagen \& Bleijenberg, 2002), which necessitates examining further the correlation between them.

\section{Material Studied}

66 people with a confirmed oncological diagnosis were included in the study, 36 of whom were undergoing radiotherapy at the time of the study. 30 of the examined people have undergone radiotherapy and are presently long-term survivors who have lived over five years after being diagnosed with the disease. The examined people are aged 40-80. The average age of the patients in the examined group is Mean $=58.4(\mathrm{SD}=10.8)$ years of age.

The examined people are divided into the following groups:

1) patients currently undergoing radiotherapy $(\mathrm{n}=36)$

2) people who have lived over 5 years from the moment they were diagnosed to the time the study was initiated $(\mathrm{n}=30)$

Demographic data: the examined people are divided into the following groups: based on age: 40-50 years of age -18; 51-64 years of age -29 and 65-80 years of age - 19; based on marital status: 42 married, 4 unmarried, 6 divorced, 14 widowed; based on the place of residence: 37 in a city, 16 in a town, 13 in a village; based on education: 6 primary education, 32 secondary education, 28 university education; based on employment: employed - 37, unemployed - 5, retired - 24; based on their incomes (at the discretion of the examined people): minimum -16, good - 46, very good -4 .

Medical data: Groups of examined people based on the diagnosis: mammary gland carcinoma radical mastectomy (complete removal of the breast) $(\mathrm{n}=23)$, mammary gland carcinoma quadrantectomy (removal of part of the breast) $(n=22)$, cervical carcinoma $(n=5)$, colorectal carcinoma $(n=5)$; other localizations $(n=11)$; based on the stage of the disease: I-II stage - 52, III -IV stage - 14; based on the treatment: surgical - 60 have been operated on, 6 have not 
been operated on; chemotherapy - 32 have undergone chemotherapy, and 16 people to whom it has not been prescribed, 18 people to whom a hormone therapy has been prescribed and they are currently applying it; radiotherapy - 36 people were undergoing radiotherapy at the time of the study, 30 of the people have undergone radiotherapy and are presently long-term survivors who have lived over five years from the moment they were diagnosed to the time the study was initiated.

\section{Area Descriptions}

To examine the burden of fatigue among patients with oncological diseases undergoing radiotherapy and long-term survivors and determine the effect of optimism on the burden of fatigue.

\section{Methods}

The study was conducted on the territory of the Complex Oncological Centers in the city of Stara Zagora and the city of Burgas. After examining the documents, 85 patients were said to meet the inclusion criteria. All the patients were asked to take part in the study and 66 of them signed an informed agreement for participation in it.

4.1 A questionnaire on the socio-demographic features, the diagnosis and data about the disease. It has been made of 12 clearly formulated questions and includes some socio-demographic and medical data about 66 examined people. The questions give information about the age, the sex, the settlement, the marital status, the level of education, the economic status of the examined people, the diagnosis, the year of diagnosing, the stage of the disease and the type of the conducted treatment.

4.2 MFI-20-Multidimensional questionnaire on fatigue (Smets, Garssen, Bonke \& De Haes, 1995).

A multidimensional tool for assessing fatigue. It has been additionally validated to be used for patients with cancer during the conducted study of 275 patients undergoing radiotherapy (Smets, Garssen, Cull \& de Haes, 1996.). The questionnaire (MFI-20) consists of five scales: general fatigue; physical fatigue; mental fatigue; decreased activity; decreased motivation, each of which contains four questions. It has been intended for patients with an oncological disease. The examined people give answers using a five-degree scale in a Likert format from 1 (yes, it is true) to 5 (no, it is not true). The results from each sub-scale range from 4 (lack of fatigue) to 20 (maximum fatigue).

4.3 Method of examining the generalized expectations about the valence of the obtained results (Velichkov, Radoslavova \& Rasheva, 1993)

The questionnaire contains 21 items which are assessed by the examined people on the grounds of a 5-degree Likert scale and summarizes the results based on two sub-scales: optimism and negative expectations. Questions 3, 5, 6, 7, $10,11,13,14,16,19,21$ form the optimism sub-scale, questions 1, 2, 4, 8, 9, 12, 15, 17, 18, 20 form the negative expectations sub-scale. The examined people have indicated the degree of their consent regarding each question choosing between 1 (I totally disagree), 2 (I agree to a certain extent), 3 (I partially agree), 4 (I agree to a large extent), 5 (I totally agree). The higher results show greater optimism and the lower results show a lower level of optimism, respectively.

\section{The Empirical Data Have Been Processed Using the Statistical Programme SPSS}

T-test of Student has been applied to compare the mean values of two independent extracts as well as a correlation analysis of Pearson to establish the statistically important correlations between the variables in the study. A regression analysis to assess the funcional dependence between two or more random quantities.

\section{Results}

The comparison between the two groups - 1. Patients currently undergoing radiotherapy and 2. over-five-year survivors in terms of severity of fatigue showed signifficant differences. The patients in the first group who are currently undergoing radiotherapy experience more severe fatigue compared to over-five-year survivors (Table 1). These results supports other authors' ideas that the fatigue severity increases with the cumulative dose of radiation and probably correlates with the duration of the treatment. (Jane, Gary, Joseph, Karen \& Paul, 2005).

In addition, the group of long-term survivors tends to experience persisting moderate fatigue. This is the reason why we can make the assumption that the symptoms of fatigue do not regress and that it exists at medium levels among 
the long-term survivors. In this context, Kyrdalen and the co-authors (Kyrdalen, Dahl, Hernes, Cvancarova \& Fossa, 2010) have discussed radiotherapy as a factor related to the existence of fatigue even among patients who have survived prostate gland carcinoma.

Table 1. Significance of the Differences between the Fatigue of Radiotherapy Patients and Survivors over Five Years

\begin{tabular}{ccccc}
\hline Patients being examined & $\mathrm{X}$ & $\mathrm{SD}$ & $\mathrm{t}$ & $\mathrm{p}$ \\
\hline Undergoing radiotherapy & 54,38 & 19,38 & 2.15 & $\mathrm{p}=0,03<0.05$ \\
Surviving over five years & 44,66 & 16,80 & & \\
\hline
\end{tabular}

Table 2. Mean Values of the Burden of Fatigue for Its Individual Dimensions within the Two Groups of Examined Patients Currently Undergoing Radiotherapy and Surviving over Five Years

\begin{tabular}{|c|c|c|c|c|c|}
\hline \multirow{2}{*}{$\begin{array}{l}\text { Dimensions of } \\
\text { fatigue }\end{array}$} & \multirow{2}{*}{$\begin{array}{l}\text { Mean }(\mathrm{SD}) \\
\text { Undergoing radiotherapy }\end{array}$} & \multirow{2}{*}{$\begin{array}{l}\text { Mean(SD) } \\
\text { Surviving over } \\
\text { five years }\end{array}$} & \multicolumn{3}{|c|}{$\underline{\mathrm{t}-\text { Test }}$} \\
\hline & & & $\mathrm{t}$ & df & $\mathrm{p}$ \\
\hline General fatigue & $11.8(4.5)$ & $10.06(4.1)$ & 1.421 & 64 & .160 \\
\hline Physical fatigue & $11.33(4.8)$ & $10.13(4.3)$ & 1.048 & 64 & .299 \\
\hline Decreased activity & $12.61(4.6)$ & $9.06(3.9)$ & 3.289 & 64 & .002 \\
\hline Decreased motivation & $10.05(4.5)$ & $8.04(3.2)$ & 2.069 & 64 & .043 \\
\hline Mental fatigue & $8.58(4.7)$ & $7.2(3.9)$ & 1.273 & 64 & .208 \\
\hline
\end{tabular}

Note: The higher numbers for each dimension reflect a higher degree of fatigue (4 - minimum, 20 - maximum).

When comparing the two groups of examined patients in terms of the burden of fatigue for its individual dimensions, a considerably higher level of burden of fatigue was detected in the dimensions of decreased motivation $(\mathrm{t}=2.06$, $\mathrm{p}=0.04<0.05)$ and decreased activity $(\mathrm{t}=3.28, \mathrm{p}=0.02<0.05) \mathrm{df}(64)$ among the patients currently undergoing radiotherapy compared to the patients who have survived over five years. As regards the dimesions of general fatigue, physical fatigue and mental fatigue, no statistically significant differences have been found (Table 2).

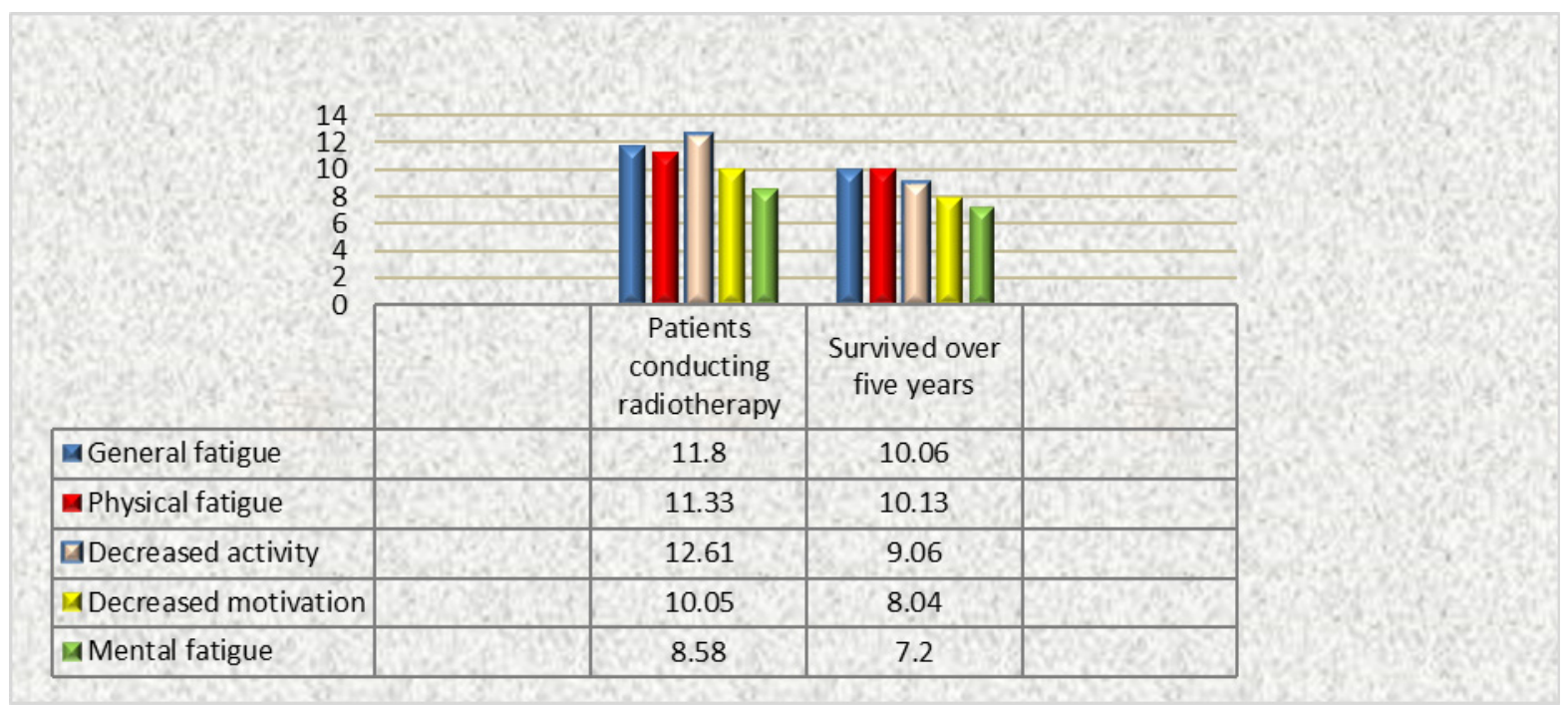

Figure 1. Average Fatigue Burden for the Individual and Dimensions within the Two Examined Groups of Patients Currently Undergoing Radiotherapy and Surviving over Five Years

Note: The higher numbers for each dimension reflect a higher degree of fatigue (4 - minimum, 20 - maximum). 
This result has been partly confirmed by a study among patients undergoing radiotherapy (Furst \& Ahsberg, 2001) and long-term survivors with colorectal carcinoma (Thong, Floortje, van de Poll-Franse, Sprangers, van der Rijt, Barsevick, Knoop \& Husson, 2017). The authors have informed of substantial differences in the dimensions of physical fatigue and decreased activity whereas regarding the dimension of mental fatigue, no significant differences have been found in the two studies. When examining the obtained results, we can see that the burden of fatigue in the two groups of examined people is average in terms of burden for each of its dimensions (Fig.1).

Table 3. Relation between Optimism, Negative Expectations and Individual Dimensions of Fatigue

\begin{tabular}{llllllll}
\hline & 1 & 2 & 3 & 4 & 5 & 6 & 7 \\
\hline 1. General fatigue & 1 & $871^{* *}$ & $488^{* *}$ & $690^{* *}$ & $520^{* *}$ & $-298^{*}$ & $371^{* *}$ \\
2. Physical fatigue & & 1 & $571^{* *}$ & $790^{* *}$ & $561^{* *}$ & $-432^{* *}$ & $474^{* *}$ \\
3. Decreased motivation & & & 1 & $692^{* *}$ & $655^{* *}$ & $-506^{* *}$ & $437^{* *}$ \\
4. Decreased activity & & & & 1 & $510^{* *}$ & $-499^{* *}$ & $436^{* *}$ \\
5. Mental fatigue & & & & 1 & $-447^{* *}$ & $337^{* *}$ \\
6. Optimism & & & & & 1 & $-437^{* *}$ \\
7. Negative expectations & & & & & & & 1
\end{tabular}

Note: The data are analyzed with the Pearson linear correlation coefficient; the correlation is statistically significant: $* p<0.05 ; * *<<0.01$

For the purpose of examining the relation between optimism, the negative expectations and the separate dimensions of fatigue, we made a correlation analysis. The results from the conducted analysis show the existence of a number of statistically significant correlations between optimism, the negative expectations and the separate dimentions of fatigue (Table 3). In terms of strength, optimism is in a weak but significant correlation with general fatigue, in a medium negative correlation with physical fatigue and the decreased activity, the decreased motivation and mental fatigue. Such is the relation between optimism and negative expectations. Subsequently, the higher the optimistic expectations, the lower the levels of burden of fatigue and vice versa. On the other hand, the negative expectations significantly correlate with general fatigue, physical fatigue, decreased activity, decreased motivation and mental fatigue.

Table 4. Comparison between the Group of Patients Currently Undergoing Radiotherapy and Survivors over Five Years in Terms of the Levels of Optimism and Negative Expectations

\begin{tabular}{llrrrl}
\hline & & Mean $(\mathrm{X})$ & \multicolumn{1}{c}{ SD } & \multicolumn{1}{c}{$\mathrm{t}$} & $\mathrm{p}$ \\
\hline Optimism & Undergoing radiotherapy & 40,41 & 11,26 & 1,73 & 0.05 \\
& Surviving over five years & 44,56 & 7,24 & & \\
Negative expectations & Undergoing radiotherapy & 26,00 & 7,73 & 0.30 & - \\
& Surviving over five years & 25,46 & 6,34 & & \\
\hline
\end{tabular}

When comparing the two groups of examined patients in terms of their levels of optimism and negative expectations (Table 4), substantial differences have been found. The patients currently undergoing radiotherapy show much lower levels of optimism $(x=40,41)$ compared with the group of those surviving over five years $(x=44,56)(t=1,73, p=0.05)$ (Fig. 2). As regards negative expectations, no statistically significant differences have been established between the group of those currently undergoing radiotherapy $(x=26,00)$ and the group of those surviving over five years $(\mathrm{x}=25,46)(\mathrm{t}=0.30)$. 


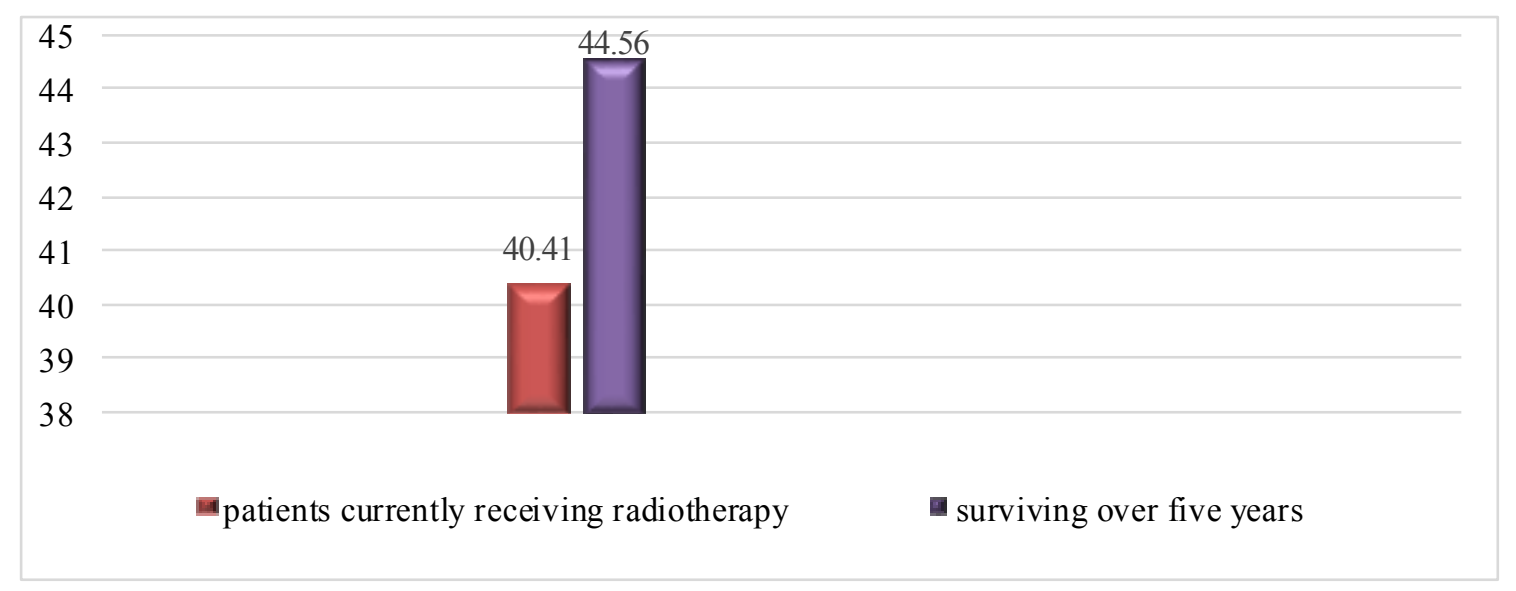

Figure 2. Mean Values of Optimistic Levels among radiotherapy Patients and Survivors over Five Years

These results confirm the conclusions of (Henselmans, Fleer, de Vries, Baas, Sanderman \& Ranchor, 2010) stating that optimism is a predictor of the assumptions of control over the treatment among patients with malignant oncological diseases. The problems related to health and their treatment allow us to judge if optimism, as a generalized expectation, gives an opportunity for short-term and/or long-term benefits related to the physical and emotional well-being. In this regard, the lower levels of optimism within the group of the patients currently undergoing radiotherapy could be explained with the fact that when being actively treated, they still feel insecure about the control over the treatment of the disease unlike the patients in the group of the long-term survivors who, through their personal experience, are convinced in the possibility to control the treatment of the disease.

Table 5. Significance of the Differences between the Examined People with Pronounced and Low Optimism in Terms of the Burden of the Fatigue for the Individual and the Dimensions

\begin{tabular}{lcccc}
\hline Dimensions of fatigue & $\mathrm{X}$ & $\mathrm{X}$ & $\mathrm{t}$ & $\mathrm{p}$ \\
& high optimism & low optimism & & \\
\hline General fatigue & 7.75 & 13.27 & -3.15 & .006 \\
Physical fatigue & 6.75 & 14.72 & -5.06 & .000 \\
Decreased activity & 6.37 & 15.72 & -6.96 & .000 \\
Decreased motivation & 6.00 & 13.00 & -4.43 & .000 \\
Mental fatigue & 5.25 & 12.18 & -4.29 & .000 \\
\hline
\end{tabular}

In order to clarify further the interrelations between the examined variables, we examined the effect of optimism and the negative expectations, as specific features of personality, on the burden of fatigue. By using the t-test of Student, we made an analysis of the differences between the groups formed on the grounds of the level of manifestation of optimism (Table 5) and negative expectations (Table.6). As it can be seen in (Table 5), the expressed optimism is a factor affecting the burden of all dimensions of fatigue: general fatigue $(\mathrm{t}=-3.15, \mathrm{p}=.006)$, physical fatigue $(\mathrm{t}=$ $-5.06, \mathrm{p}=.000)$, decreased activity $(\mathrm{t}=-6.96, \mathrm{p}=.000)$, decreased motivation $(\mathrm{t}=-4.43, \mathrm{p}=.000)$ and mental fatigue $(\mathrm{t}=-4.29, \mathrm{p}=.000)$. Patients with a higher level of optimism show lower levels of burden of fatigue compared to patients with a low level of optimism regardless of whether they are long-term survivors or are currently undergoing radiotherapy. This leads us to the conclusion that the presence of optimism in the personality profile of people is a prerequisite for the lower burden of fatigue in the context of oncological diseases. This result has been confirmed by the data obtained from the study of (Von Ah DM et al., 2008) among patients with oncological diseases. The authors state that the higher level of optimism is related to lower levels of fatigue. 
Table 6. Significance of the Differences between the Examined Individuals with Pronounced and Low Negative Expectations in Terms of the Severity of Fatigue for Individuals and Dimensions

\begin{tabular}{lcccc}
\hline Dimensions of fatigue & $\overline{\mathrm{x}}$ & $\overline{\mathrm{x}}$ & $\mathrm{t}$ & $\mathrm{p}$ \\
& $\begin{array}{c}\text { expressed negative } \\
\text { expectations }\end{array}$ & $\begin{array}{c}\text { low negative } \\
\text { expectations }\end{array}$ & & \\
\hline General fatigue & 12.73 & 10.00 & 2.37 & .176 \\
Physical fatigue & 13.46 & 8.00 & 4.45 & .012 \\
Decreased activity & 14.60 & 8.70 & 3.08 & .005 \\
Decreased motivation & 11.86 & 6.30 & 2.73 & .000 \\
Mental fatigue & 9.93 & 5.50 & 1.39 & .026 \\
\hline
\end{tabular}

When making a comparison between the formed groups of examined patients in terms of level of manifestation of the negative expectations, we found substantial differences regarding this factor (Table 7). It turned out that the expressed negative expectations are a factor affecting the burden of the dimensions of physical fatigue $(\mathrm{t}=4.45, \mathrm{p}$ $=.012)$, decreased activity $(\mathrm{t}=3.08, \mathrm{p}=.005)$, decreased motivation $(\mathrm{t}=2.73, \mathrm{p}=.000)$ and mental fatigue $(\mathrm{t}=1.39$, $\mathrm{p}=.026)$. Patients with high negative expectations manifest considerably greater fatigue regarding the dimensions and physical fatigue, decreased activity, decreased motivation and mental fatigue. It is interesting to see from the obtained results that the negative expectations are not significantly related to the dimension of general fatigue.

Table 7. Regression Analysis of the Influence of Optimism and Negative Expectations on the Severity of General Fatigue, Physical Fatigue and Decreased Activity, Decreased Motivation and Mental Fatigue in the Groups of the Subjects Examined

\begin{tabular}{lllll}
\hline & Beta & $\mathrm{p}$ & $\mathrm{F}$ & $\mathrm{R}^{2}$ \\
\hline Optimism & & & & \\
Undergoing radiotherapy & & & & \\
Physical fatigue & -0.41 & $\mathrm{p}<0.01$ & 6.86 & $0.144(14.4 \%)$ \\
Decreased activity & -0.47 & $\mathrm{p}<0.004$ & 9.73 & $0.200(20.0 \%)$ \\
Decreased motivation & -0.46 & $\mathrm{p}<0.004$ & 9.58 & $0.197(19.7 \%)$ \\
Mental fatigue & -0.41 & $\mathrm{p}<0.01$ & 7.20 & $0.151(15.1 \%)$ \\
Surviving over five years & & & & \\
General fatigue & -0.42 & $\mathrm{p}<0.02$ & 6.01 & $0.148(14.8)$ \\
Physical fatigue & -0.44 & $\mathrm{p}<0.01$ & 7.02 & $0.172(17.2 \%)$ \\
Decreased activity & -0.45 & $\mathrm{p}<0.01$ & 7.27 & $0.206(26.0 \%)$ \\
Decreased motivation & -0.50 & $\mathrm{p}<0.04$ & 9.68 & $0.230(23.0 \%)$ \\
Mental fatigue & -0.46 & $\mathrm{p}<0.01$ & 7.61 & $0.214(21.4 \%)$ \\
Negative expectations & & & & \\
Undergoing radiotherapy & & & & \\
General fatigue & 0.31 & $\mathrm{p}<0.05$ & 3.82 & $0.101(10.1 \%)$ \\
Physical fatigue & 0.45 & $\mathrm{p}<0.006$ & 8.67 & $0.203(20.3 \%)$ \\
Decreased activity & 0.41 & $\mathrm{p}<0.01$ & 7.19 & $0.150(15.0 \%)$ \\
Decreased motivation & 0.36 & $\mathrm{p}<0.03$ & 5.07 & $0.104(10.4 \%)$ \\
Surviving over five years & & & & \\
General fatigue & 0.45 & $\mathrm{p}<0.01$ & 7.30 & $0.170(17.0 \%)$ \\
Physical fatigue & 0.51 & $\mathrm{p}<0.04$ & 9.90 & $0.235(23.5 \%)$ \\
Decreased activity & 0.52 & $\mathrm{p}<0.03$ & 10.58 & $0.248(24.8 \%)$ \\
\hline
\end{tabular}


In order to make a more precise analysis of the strength and the direction of the interrelations, more significant mediator effects need to be found. After the performed regression analysis of the influence of optimism (Table 7) and the negative expectations on the individual dimensions of fatigue for each of the examined groups, it became clear that in the group of patients undergoing radiotherapy, optimism can statistically significantly predict the burden of physical fatigue (Beta $=-0.41 ; \mathrm{p}<0.01$ ), decreased activity $(\mathrm{Beta}=-0.47 ; \mathrm{p}<0.004)$, decreased motivation $(\mathrm{Beta}=-0.46$; $\mathrm{p}<0.004)$, mental fatigue $(\mathrm{Beta}=-0.41 ; \mathrm{p}<0.01)$. As regards the group of patients who have survived five years, optimism can statistically significantly predict the burden of general fatigue (Beta $=-0.42 ; \mathrm{p}<0.02$ ), physical fatigue (Beta $=-0.44 ; \mathrm{p}<0.01$ ), decreased activity (Beta $=-0.45 ; \mathrm{p}<0.01$ ), decreased motivation (Beta $=-0.50 ; \mathrm{p}<0.04$ ), mental fatigue $(\mathrm{Beta}=-0.46 ; \mathrm{p}<0.01)$. We can see that optimism is the most significant predictor of decreased activity $\mathrm{F}=(9.73), \mathrm{p}<0.004$; and decreased motivation $\mathrm{F}=(9.58), \mathrm{p}<0.004$ within the group of patients undergoing radiotherapy. The obtained values of the corrected determination coefficient show that $20.0 \%$ of the changes in case of decreased activity and $19.7 \%$ of the changes in case of decreased motivation can be explained with the optimism of patients undergoing radiotherapy. Regarding the group of patients who have survived over five years, optimism is the most significant predictor of the dimension of decreased motivation $\mathrm{F}=(9.68), \mathrm{p}<0.04$ and the dimension of mental fatigue $\mathrm{F}=(7.61), \mathrm{p}<0.01$. The obtained values of the corrected determination coefficient show that $23.0 \%$ of the changes in case of decreased motivation and $21.4 \%$ of the changes in case of mental fatigue can be explained with optimism as a generalized expectation for obtaining good results among patients who have survived over 5 years. The results we have obtained regarding the effect of optimism on the burden of fatigue among patients with malignant diseases are confirmed by (Schou-Bredal \&Toien, 2017). The authors state that optimism has a substantinal influence on the burden of fatigue among patients with mammary gland carcinoma (OR-95, Cl 92-1.0, $\mathrm{p}=.049)\left(\mathrm{X}^{2}=5.56, \mathrm{p}=.69\right)$.

The negative expectations can statistically significantly predict the burden of general fatigue (Beta $=0.31 ; \mathrm{p}<0.05)$, physical fatigue (Beta $=0.45 ; \mathrm{p}<0.006$ ), decreased activity (Beta $=0.41 ; \mathrm{p}<0.01)$, decreased motivation (Beta $=0.36$; $\mathrm{p}<0.03$ ) among patients undergoing radiotherapy and the burden of general fatigue (Beta $=0.45 ; \mathrm{p}<0.01$ ), physical fatigue (Beta $=0.51 ; p<0.04)$, decreased activity (Beta $=0.52 ; p<0.03$ ) among the group of those who have survived over five years. We can see that the negative expectations are the most important predictor of the dimensions of physical fatigue and decreased activity in both groups of examined people: for the group of patients undergoing radiotherapy $\mathrm{F}=(8.67), \mathrm{p}<0.006 ; \mathrm{F}=(7.19), \mathrm{p}<0.01$ and for the group of people who have survived over five years $\mathrm{F}=(9.90), \mathrm{p}<0.04 ; \mathrm{F}=(10.58),(\mathrm{p}<0.03)$. The obtained values of the corrected determination coefficient show that $20.3 \%$ of the changes in physical fatigue and $15.0 \%$ of the changes in the dimension of decreased activity in the group of patients undergoing radiotherapy and $23.5 \%$ of the changes in physical fatigue and $24.8 \%$ of the changes in the dimension of decreased activity in the group of patients who have survived over five years can be explained with the negative expectations.

The conclusion we can draw based on these results is that the generalized expectations significantly affect the burden of fatigue in terms of its separate dimensions in both groups of examined people. Optimism substantially influences the decreased activity and motivation within the group of patients undergoing radiotherapy and also the decreased motivation and mental fatigue among those who have survived over five years. The negative expectations have proven to be the most important predictor of the dimensions of physical fatigue and decreased activity in both groups of examined people. We can conclude that the positive emotions extend and develop the resources of the personality. The higher level of optimism increases one's ability to find a positive meaning and experience positive emotions in everyday life. The experiencing of positive emotions boosts the flexibility of thinking and develops the personality resources for coping with the hardships of life (Petkova, 2002).

\section{Discussion}

Fatigue can be experienced by patients with oncological diseases in all stages of the disease trajectory. For most of the patients, fatigue persists years after the completion of the treatment. As regards the trends of fatigue, greater burden has been established among patients undergoing radiotherapy at the time the study was being conducted.This result has been confirmed by (Wang, Giralt, Mendoza, Engstrom, Johnson, Peterson, Broemeling \& Cleeland, 2002). The authors have established an increase in fatigue during the radiotherapy among $67 \%$ of the patients and this percentage dropped to $31 \%$ at the end of the treatment. According to the same authors, the increase in the values of fatigue during the radiotherapy may be due to the observed side effects because these effects usually emerge in the beginning of the third week of the treatment (Wang et al., 2002). According to (Jane et al., 2005), the burden of fatigue increases with the cumulative dose of radiation and can be related to the duration of the treatment. Despite 
the fact that the multidimensional nature of fatigue among patients with oncological diseases has been widely accepted (Kuhnt \& Brähler, 2010); (NCCN, 2011), we can doubt whether the dimensions of fatigue are a manifestation of one and the same symptom (multidimensional concept) or a manifestation of several phenomena which are jointly called fatigue but are in fact separate symptoms. The study that we conducted of the burden of fatigue in its separate dimensions in both types of examined patients - those undergoing radiotherapy at the time of the study and those who have survived over five years, shows interesting results. We have established statistically significant differences between the two groups in terms of burden of the fatigue for the dimensions of decreased motivation and decreased activity. The patients currently undergoing radiotherapy manifest a higher level of burden of fatigue in the dimensions of decreased motivation $(\mathrm{t}=2.06, \mathrm{p}=0.04<0.05)$ and decreased activity $(\mathrm{t}=3.28$, $\mathrm{p}=0.02<0.05) \mathrm{df}(64)$ compared to the patients in the group of those who have survived over five years. Regarding the dimensions of general fatigue, physical fatigue and mental fatigue, we have found no statistically significant differences. This result has been partly confirmed by a study of patients undergoing radiotherapy (Fürst \& Åhsberg, 2001) and long-term survivors with colorectal carcinoma (Thong et al., 2017). The authors have informed of substantial differences in the dimensions of physical fatigue and decreased activity but regarding the dimension of mental fatigue, neither of the two studies has established any major differences.

Considering the above analysis of the results obtained from our study, we have found substantial differences in the levels of optimism between the two groups of examined patients. The patients undergoing radiotherapy at that time showed much lower levels of optimism compared to the group of those who have survived over five years. These results have confirmed the conclusions of (Henselmans et al., 2010) stating that optimism is a predictor of the beliefs related to the control over the treatment among patients with malignant oncological diseases. Regarding the negative expectations, we have found no statistically significant differences between the group of those undergoing radiotherapy at that time and the group of patients who have survived over five years. The results obtained from our study show that the presence of optimism and the low negative expectations within the personality profile of the patients with oncological diseases suggest lower levels of fatigue regardless of the stage of the disease and the conducted treatment. Another interesting conclusion in this study is related to the established correlations between optimism and fatigue. We can see that the strongest correlation is that of optimism with decreased motivation ( $\mathrm{r}=$ $-0.56)$ and the weakest correlation is that with general fatigue $(\mathrm{r}=-0.26)$. The results we obtained have been confirmed by a study of (Schou-Bredal \& Toien, 2017) of 832 patients who have survived mammary gland carcinona, two to six years upon the completion of the treatment. The authors have stated that optimism correlates with fatigue siginicantly and negatively $(\mathrm{r}=-.34 ; \mathrm{p}<.0001)$ and also add that women with lower levels of optimism inform of higher levels of fatigue compared to women with a more optimistic attitude $(15.5 ; 17.7, \mathrm{p}<.0001, \mathrm{~d}=.56)$. When conducting a regression analysis of the influence of optimism and the negative expectations on the burden of fatigue, it turned out that optimism can statistically significanlty predict the burden of physical fatigue, decreased activity, decreased motivation, mental fatigue among patients undergoing radiotherapy. For the patients who have survived over five years, optimism is a major predictor of the burden of general fatigue, physical fatigue, decreased activity, decreased motivation, mental fatigue. The results we have established contradict the results obtained from the study of (Kurtz M, Kurtz J, Given C, Given B, 2008). The authors state that in their study they have found no relation between optimism and the burden of fatigue and optimism has not been determined as a major predictor of the burden of fatigue.

Based on the results from our study, we can draw the conclusion that the burden of fatigue among patients with oncological diseases in different stages of the disease trajectory can be influenced by means of psychological interventions consistent with the personality features of the patients. We need further studies to examine the relation between optimism and fatigue and the influence of optimism as a stable personality trait on the burden of fatigue in other time points of the trajectory of the oncological diseases.

\section{Conclusions}

1. The patients undergoing radiotherapy at that time show more evident burden of fatigue in the dimensions of decreased motivation and decreased activity compared to the patients in the group of the long-term survivors.

2. Optimism and negative expectations significantly correlate with the dimensions of fatigue in both groups of patients as the most clearly manifested is the negative correlation of optimism with decreased activity and decreased motivation. This leads us to interpret optimism as a predictor of the behaviour of being ill. 
3. The presence of optimism and the low negative expectations within the personality profile of patients with oncological diseases suggest lower levels of fatigue regardless of the stage of the disease and the conducted treatment.

4. As a personality factor, optimism explains mostly decreased motivation and decreased activity within the group of patients undergoing radiotherapy and decreased motivation and mental fatigue within the group of the long-term survivors. This result can be interpreted in the context of optimism as a more sigificant behavioural predictor among patients undergoing radiotherapy. This leads us to assume that the behavioural techniques would be more useful in this group whereas for the long-term survivors, it would be more appropriate to apply cognitive and cognitive-behavioural therapeutic approaches.

5. The established differences in the burden of fatigue depending on optimism among the examined groups of patients with oncological diseases can be the subject of a future study on this issue.

\section{References}

Allison, P. J., Guichard, C., \& Gilain, L. (2000). A prospective investigation of dispositional optimism as a predictor of health-related quality of life in head and neck cancer patients. Quality of Life Research, 9(8), 951-960. http://dx.doi.org/10.1023/A:1008931906253

Bower, J. E. (2014). Cancer-related fatigue: Mechanisms, risk factors, and treatments. Nat Rev Clin Oncol, 11(10), 597-609. https://doi.org/10.1038/nrclinonc.2014.127

Bower, J. E., Ganz, P. A., Desmond, K. A., Bernards, C., Rowland, J. H., Meyerowitz, B. E., \& Belin, T.R. (2006). Fatigue in long-term breast carcinoma survivors. Cancer, 106(4), 751-758. https://doi.org/10.1002/cncr.21671

Bower, J. E., Ganz, P. A., Desmond, K. A., Rowland, J. H., Meyerowitz, B. E., \& Belin, T. R. (2000). Fatigue in breast cancer survivors: occurrence, correlates, and impact on quality of life. J Clin Oncol., 18, 743-753. https://doi.org/10.1200/JCO.2000.18.4.743

Carver, CS., Pozo, C., Harris, S. D., Noriega, V., Scheier, M., F, Robinson, D. S., Ketcham, A. S., Moffat, F.L. Jr., \& Clark K. C. (1993). How coping mediates the effect of optimismondistress: A study of women with early stage breast cancer. J Pers Soc Psychol, 65, 375-390. https://doi.org/10.1037/0022-3514.65.2.375

de Vries U., Reif, K., \& Peterman, F. (2011). Tumorbedingte Fatigue und ihre psychosozialen Belastungen November 2011, 85-92.

Furst, C., \& Ahsberg, E. (2001). Dimensions of fatigue during radiotherapy. Supportive Care in Cancer, 9(5), 355-360. https://doi.org/10.1007/s005200100242

Henselmans, I., Fleer, J., de Vries, J., Baas, P.C., Sanderman, R., \& Ranchor, A. V. (2010). The adaptive effect of personal control when facing breast cancer: cognitive and behavioural mediators. Psychology and Health, 25(9), 1023-1040. https://doi.org/10.1080/08870440902935921

Jane, T. H., Gary, R. M., Joseph, A. R., Karen, M., \& Paul, O. (2005). Occurrence, severity, and longitudinal course of twelve common symptoms in 1129 consecutive patients during radiotherapy for cancer. J Pain Symptom Manage, 30, 433-442. https://doi.org/10.1016/j.jpainsymman.2005.04.012

Kuhnt, S., \& Brähler, E. (2010). Tumorassoziierte Fatigue. Psychother Psych Med., 60, 402-411. https://doi.org/10.1055/s-0030-1248590

Kurtz, Margot., E., Jay, C., Kurtz, Charles, W., Given, Barbara, A., \& Given. (2008).Patient Optimism and Mastery-Do They Play a Role in Cancer Patients' Management of Pain and Fatigue? Journal of Pain and Symptom Management, 36 (1), 1-10. https://doi.org/10.1016/j.jpainsymman

Kyrdalen, A., E., Dahl, A., A, Hernes, E., Cvancarova., M., \& Fossa, S., D. (2010). Fatigue in hormone-naive prostate cancer patients treated with radical prostatectomy or definitive radiotherapy. Prostate Cancer Prostatic Dis., 13, 144-150. https://doi.org/10.1038/pcan.2009.61

Miller, D. L., Manne, S., L., Taylor, K., Keates, J., \& Dougherty, J. (1996). Psychological distress and well-being in advanced cancer: the effects of optimism and coping. J Clin Psychol Med Settings, 3, 115-130. https://doi.org/10.1007/BF01996132

National Comprehensive Cancer Network. (2011). Clinical practice guidelines in oncology. Cancer related fatigue.

Petkova, M. (2002). Subjective well-being and health. Kota, Stara Zagora 
Petkova, M., \& Nikolov, V. (2011). Anger, depression and pain in patients with oncological diseases. Bulgarian Journal of Psychology. Collection of scientific reports. Sofia. 3(4), 597-602

Rotonda, C., Guillemin, F., Bonnetain, F., Velten, M., \& Conroy, T. (2013). Factors Associated With Fatigue After Surgery in Women With Early-Stage Invasive Breast Cancer. The Oncologist, 18, 467-47. https://doi.org/10.1634/theoncologist.2012-0300

Scheier, M., F., \& Carver, C., S. (1987). Dispositional optimism and physical well-being: the influence of generalized expectanci es on health. Journal of Personality, 55, 169-210. http://dx.doi.org/10.1111/j.1467-6494.1987.tb00434

Schou-Bredal, I., \& Toien, K. (2017). Is Dispositional Optimism Associated with Fatigue in Breast Cancer Survivors? Psychology, 8, 1762-1773. https://doi.org/10.4236/psych.2017.811116

Servae, S. P., Verhagen, C., \& Bleijenberg, G. (2002a). Fatigue in cancer patients during and after treatment: prevalence, correlates and interventions. Eur $J$ Cancer, 38(1), 27-43. https://doi.org/10.1016/S0959-8049(01)00332-X

Simon AM., \& Zittoun R. (1999). Fatigue in cancer patients. Curr Opin Oncol., 11(4), 244-9. https://doi.org/10.1097/00001622-199907000-00002

Smets, EM., Garssen, B., Bonke, B., \& De Haes, JC. (1995). The Multidimensional Fatigue Inventory (MFI) psychometric qualities of an instrument to assess fatigue. $J$ Psychosom Res, 39(3), 315-325. https://doi.org/10.1016/0022-3999(94)00125-O

Smets, EM., Garssen, B., Cull, A., \& de Haes, JC. (1996). Application of the multidimensional fatigue inventory (MFI-20) in cancer patients receiving radiotherapy. $B r \quad J$ Cancer, 73(2), 241-245. https://doi.org/10.1038/bjc.1996.42

Stone, P., Richards, M., \& Hardy, J .(1998). Fatigue i n patients with cancer. Eur J Cancer, 34(11), 1670-6. https://doi.org/10.1016/S0959-8049(98)00167-1

Thong, M., Floortje, M., van de Poll-Franse, L., Sprangers, M., van der Rijt, C., Barsevick, A., Knoop, H., \& Husson, O. (2018). Identifying the subtypes of cancer-related fatigue: results from the population-based PROFILES registry. Journal of Cancer Survivorship, 12(1), 38-46. https://doi.org/10.1007/s11764-017-0641-0

Valerianova, Z., Dimitrova, N., \& Atanasov, T. (2013). Cancer Illness in Bulgaria. Bulgarian National Cancer Registry, $X X I V(\mathrm{v}), 12-54$.

Velichkov, A., M., Radoslavova, M., \& Rasheva. (1993). Method for Measuring the Generalized Expectations for Valency of Results (Optimism and Negative Expectations). Bulgarian Journal of Psychology, 3, 85-100.

Von Ah D.M., Kang D.H., \& Carpenter J.S. (2008). Predictors of cancer-related fatigue in women with breast cancer before, during, and after adjuvant therapy. Cancer Nurs, 31, 134-144. https://doi.org/10.1097/01.NCC.0000305704.84164.54.

Wang, X., S., Giralt, S., A., Mendoza, T., R., Engstrom, M., C., Johnson, B.,A, Peterson, N., Broemeling, L.,D, \& Cleeland, C., S. (2002). Clinical factors associated with cancer-related fatigue in patients being treated for leukemia and non-Hodgkin's Lymphoma. $J$ Clin Oncol., 20(5), 1319-28. https://doi.org/10.1200/JCO.2002.20.5.1319

Weis, J., \& Falle, H. (2012). Psychosoziale Folgen bei Langzeitüberlebenden einer Krebserkrankung, Marz505-508

Woo, B., Dibble, S., L, Piper, B. F., Keating, S. B., \& Weiss, M. C. (1998). Differences in fatigue by treatment methods in women with breast cancer. Oncol Nurs Forum, 25, 915-20. 